\title{
Antimicrobial Characteristics of Essential Oil of the Origanum vulgare L.
}

\author{
N.A. Agayeva ${ }^{1}$, S.R. Rafiyeva $^{2}$, G.Sh. Shiraliyeva ${ }^{1}$ and S.J. Ibadullayeva ${ }^{2 *}$ \\ ${ }^{1}$ Azerbaijan Medical University, Azerbaijan \\ ${ }^{2}$ Institute of Botany of the ANAS, Azerbaijan \\ *Corresponding author
}

\begin{tabular}{|c|c|}
\hline \multicolumn{2}{|r|}{ A B S T R A C T } \\
\hline Keywords & \multirow{4}{*}{$\begin{array}{l}\text { Amount of the essential oil of the Origanum vulgare L. (Lamiaceae Lindl.) } \\
\text { is In the phase of blossoming essential oil was obtained from the fresh mass } \\
0,07-0,2 \% 1,4-2 \% \text { and dry mass } 0,2-0,7 \% \text { of its surface part, light } \\
\text { refraction rate is } \mathrm{n}_{\mathrm{D}}{ }^{20}-1.4980, \mathrm{D}^{20}{ }_{20}-0,964 \text {, Acid number is } 0,8-1,28 \text {; } \\
\text { essence number is } 7,6 \text {; after acetillation essense number became } 54,88 \text {. The } \\
\text { main components of oil are: timol - about } 2,2-6,7 \% \text {, bisyclic sesquiterpens } \\
-12,5 \% \text {, free spirits - } 12,8-15,4 \% \text {, heranilacetat }-2,63 \% \text { and other } \\
\text { substances. Antimicrobial properties of the essential oils of the species } \\
\text { O.vulgare have been studied as well as it was ascertained that essaential } \\
\text { oils of the can be used as antifungal means. }\end{array}$} \\
\hline $\begin{array}{l}\text { Essential oil, } \\
\text { Origanum vulgare, } \\
\text { Staphylolococcus } \\
\text { aureus, Eseherichia } \\
\text { coli, Pseudomosa } \\
\text { auriginosa, Candida } \\
\text { albicans. }\end{array}$ & \\
\hline Article Info & \\
\hline $\begin{array}{l}\text { Accepted: } \\
\text { 17 October } 2017 \\
\text { Available Online: } \\
10 \text { December } 2017\end{array}$ & \\
\hline
\end{tabular}

Introduction

About 800 essential oil plants have been formed in the rich and various vegetation cover of Azerbaijan. As a continuation of the conducted experimental investigations essential oils have been obtained from the various bodies of Lamiateae Lindl. family in different years (Ibrahimov et al., 1996; Gasymov, 2006; Mammadova et al., 2011). Output rate of the essential oil of the Origanum vulgare which are representatives of shizocalis section was defined during all phases of the vegetation.

On medicinal purposes its upper part is used in the period of blossom. It cotains essential oil, carvacrol, independent spirits, tanines, bitter substances, mineral salts, vitam in C, choline, flavonoids, tanning substances, geranilacetate Origanum calms the central nervous system, increases panceras secretion of digestion system as well as bronchial and sweet glands, accelerates peristaltics of guts, renders anestesia and desodoration effects to them. It is used both as internal and external in the infusion and broth states. In folk medicine it is used at: inflammation of erysipelatous, mouth cavity, larynx, pharyngitis, tooth aches, furuncles, different types of skin eruptions, reumatism, cholecistit, stomach spasm, appetite absence, anti-cough, paralich and epylepsy. It is met in Azerbaijan around botanical and 
geographycal region of Small Caucasus, in Gekgel, Dashkesan, all regions of the Nakhichevan AR, Talysh as well as towards Shamakhi and Guba-Gusar of the Great Caucasus. Origanum L. (Lamiaceae Lindl.) in Azerbaijan flora, there is of 1 (Origanum vulgare L.) species. There are many essential oil in the leaf of complete.

Many new fields of the essential oils use have been ascertained. As the essential oils consist of compounds, i.e. set of bioactive substances it uniquely affects to human body physiologically, psychologically, curatively (Ibadullayeva et al., 2007). Essential oils don't lose their quality and they continue remaining safe and effective even if they were conserved for a long period.

Accumulation dynamics of the essential oil in these plant were defined in different stages of onthogenesis and it was realised that it occured during the florescence phase of the generative period most often. In the accumulation dynamics of the essential oil the synthesis runs weakly at first, maximum output of the essential oil occures in the leaf; recurrent reduce is observed in the next phases.

Essential oils obtained of these species are used in making various canning products of food industry, in perfumery and cosmetics, as well as in medicine. Structure of the essential oils was composed of valuable components as: fenol, terpen, timol (Goryayev, 1952). Separate obtaining of these components is also possible in the production condition by their extraction out of the essential oil. Essential oil of $O$. vulgare is used in making toothpastes, antiseptic substances, as well as balsam and tinctures are used against weakness, in disease of nervous system and respiratory disease, anaemia, gastrointestinal disease, cholagogue, expectorant and other diseases. It is used as indispensable spicery in food industry. From the other hand it is considered as valuable nectar. People use its top with blossom in fresh and dry states. Amount of vitamin $\mathrm{C}$ in the plant is $56 \mathrm{mg} / \%$.

\section{Materials and Methods}

The investigated by us species are widely spread mostly in forests, bushy, forest glades, steppes, orchards and meadows of Azerbaijan as: Origanum vulgare L. in the low and middle belts of the Shahbuz (Nakhichevan Autonomous Republic), Shaki (The Big Caucasus) and Gedebey (The Small Caucasus).

The phenological observations were held on the base of Beydman Methods during the whole season (Beydman, 1974). Output rate of the essential oil was defined by the Ginsberg Method (Ginzberg, 1932).

Essential oils were defined by means of disk diffusion and purification series method applied against microbes.

\section{Experimental part}

In the phase of blossoming essential oil was obtained from the fresh mass $0,07-0,2 \% 1,4-$ $2 \%$ and dry mass $0,2-0,7 \%$ of its surface part light refraction rate is $\mathrm{n}_{\mathrm{D}}{ }^{20}-1.4980, \mathrm{D}^{20}{ }_{20}$ 0,964 . Essential oil of the plant is a grayish and yellow substance. It is dissoluble (1:7) in the $90 \%$ spirit. When increasing amount of essential oils in spirit its colour changes and grows turbid. Essential oil of Origanum vulgare L. is plesant-smelled and has got a pritty bitter taste. Acid number is $0,8-1,28$; essence number is 7,6; after acetillation essense number became 54,88. The main components of oil are: timol - about 2,2$6,7 \%$, bisyclic sesquiterpens - 12,5\%, free spirits - 12,8-15,4\%, heranilacetat - 2,63\% and other substances. Taking into account all of these essential oils obtained of the abovementioned plants have been microbiologically investigated. 
The investigation was held in the Microbiology Department of the (AMU) Azerbaijan Medical University and in the Ethnobotany Laboratory of (IB ANAS) the Institute of Botany of the Azerbaijan National Academy of Sciences as a component a joint research works conducted according to the agreement on the scentific collaboration signed between AMU and IB of the ANAS.

Disk diffusion and purification series method were applied. E-coli have been taken as a testculture. A suspension with 1 mgr microcell in $1 \mathrm{ml}$ has been made from a microorganism culture of a day (24 hours). Then the suspension was added into Petri vessel with Sabouraud's peptone agar in it as well this was equally spread onto medium surface. The rest fluid was sucked by a pipet and this vessel has being dried in a thermostate during 10-15 minutes. A sterile filter paper put the disks onto that surface wetting them by preparations plased it into a thermostate; the result has been registered after its cultivasion in the thermostate for $18-24$ hours at $37^{\circ} \mathrm{C}$ temperature. A sterile space of $20 \mathrm{~mm}$ was otained in the Origanum vulgare.
In the purification series method 5 sterile sample bottles were taken, $1 \mathrm{ml}$ substans was poured into the $1^{\text {st }}$ and $2^{\text {nd }}$ bottles, $1 \mathrm{mg}$ abacterial liquid petrolatun was added into all sample bottles beginning from the $2^{\text {nd }}$ one. Then $1 \mathrm{ml}$ mixture was taken out of the $2^{\text {nd }}$ bottle was poured into the $3^{\text {rd }}$ one, it was passed out of the $3^{\text {rd }}$ into the $4^{\text {th }}$ one, and out of the $4^{\text {th }}$ into the $5^{\text {th }}$ sample bottle; $1 \mathrm{ml}$ mixture from the $5^{\text {th }}$ bottle was poured away. So, essential oils in the sample bottles got: in the $1^{\text {st }}$ bottle - pure, i.e., as it was before; in the $2^{\text {nd }}$ bottle - twice purified; in the $3^{\text {rd }}$ one 4 times purified; in the $4^{\text {th }}$ one -8 times purified; and in the $5^{\text {th }}$ bottle -16 times purified.

After the purification a drop of the microbe suspension was added into each sample bottle by means of a Paster piptte. Then, after the exposisions for: 10 minutes, 20 minutes, 40 minutes, and 60 minutes sowing was conducted onto the located in the Petri vessel in each sample bottle. The results were registered after keeping the sowings in a thermostat of $37^{0} \mathrm{C}$ for 24 hours.

Table.1 Effect of Origanum vulgare essential oils onto bacilli (E. coli)

\begin{tabular}{|c|c|c|}
\hline $\begin{array}{l}\text { Exposition } \\
\text { duration }\end{array}$ & Origanum vulgare & $\begin{array}{c}\text { vaseline (controle) } \\
\text { oil }\end{array}$ \\
\hline & $\begin{array}{lllll}1 & 2 & 3 & 4 & 5\end{array}$ & $\begin{array}{lllll}1 & 2 & 3 & 4 & 5\end{array}$ \\
\hline 10 minutes & $-\quad-\quad+\quad+$ & +++++ \\
\hline 20 minutes & $-\quad-\quad-\quad++$ & +++++ \\
\hline 40 minutes & $-\quad-\quad-\quad-\quad+$ & +++++ \\
\hline 60 minutes & $-\quad-\quad-\quad-\quad-$ & +++++ \\
\hline
\end{tabular}

Notation conventions:

"+" - shows the growing

"_-" - shows the absence of the growing

12345 - are the sequence number of the vessel 
Table.2 Antimicrobic effect of newly synthesised essential oils

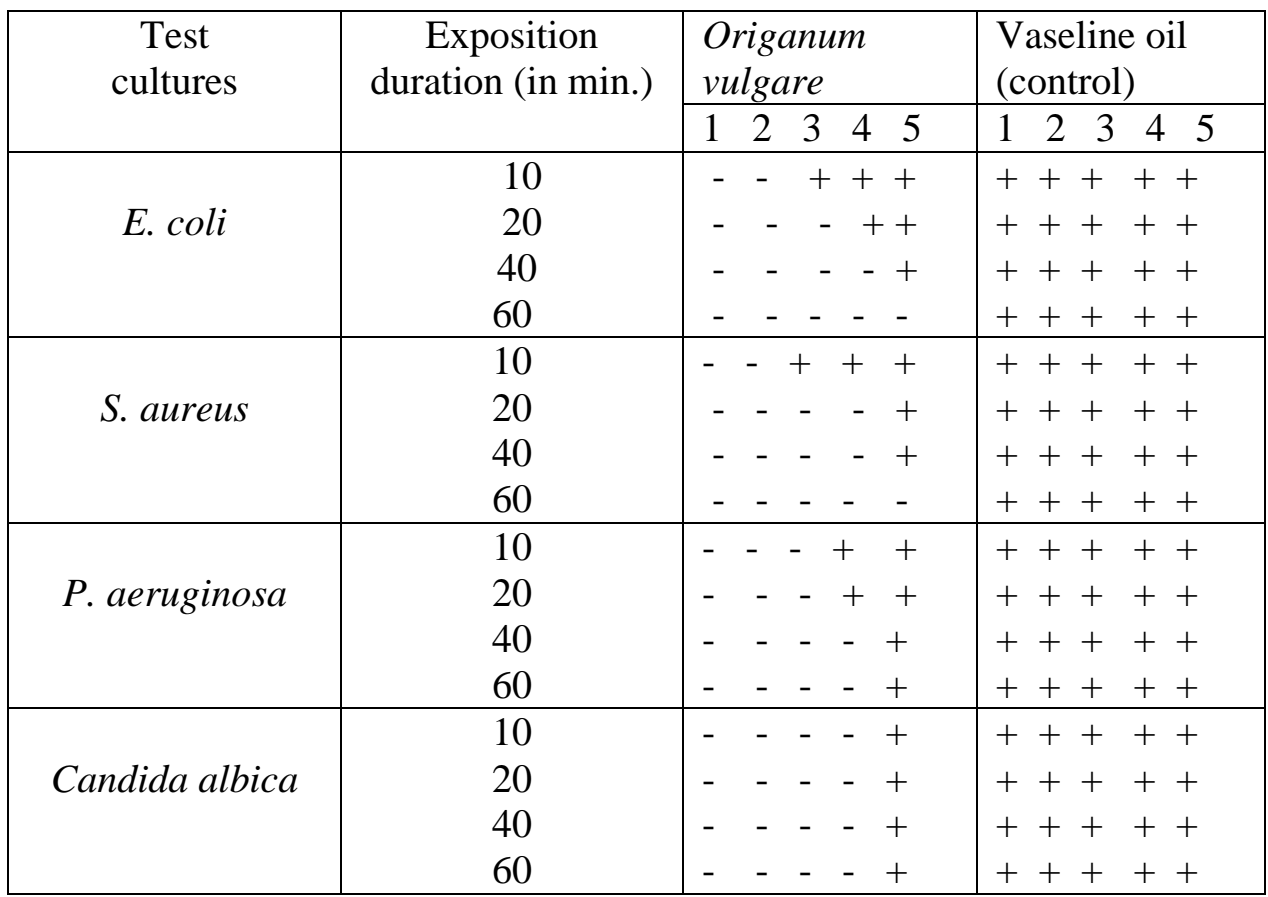

Notation conventions:

" +" - shows the complete growing

"_" - shows the absence of the growing

$1,2,3,4,5$ - are the maintenance number of the vessel

Origanum vulgare out of the newly synthesised oils can be considered as active ones with antimicrobic property. So the $2^{\text {nd }}$ bottle and the $4^{\text {th }}$ bottle in sterile state killed bacilli at onse. The $2^{\text {nd }}$ bottle - the purified form (4 times) killed bacilli in 20 minutes; and the $4^{\text {th }}$ bottle effecting more actively killed E. coli in 20 minutes even when it was purified 8 times. Purification of Origanum vulgare for 16 times took life activities of the bacilli in an hour. The results are shown in the Table 1.

In order to study antibacterial and antifungal properties of the newly synthesised essential oils Staphylolococcus aurens of gram positive bacteria as a test-culture, Eseherichia coli (bacilli) and Pseudomosa auriginosa (dark blue $\&$ green bacilluae pyogenic (hot) abscesses) of gram negative bacteria as well as Candida albicans that is leaven-shaped fungus as a representative of fungus were taken.
To study the antimicrob properties diskdiffusion and purification series methods were used. In the disk-diffusion method a suspension (posessing $1 \mathrm{mGr}$ cell in $1 \mathrm{ml}$ ) was prepared of microorganism's culture of a day. Then a little suspension was added into the Petri vessel with Sabouraud's peptone agar in it and it was equally spread onto the medium surface. The rest liquid was sucked by means of pipette and the vessel was dried in the thermostat for 10-15 minutes. Sterile filter paper disks were put on that surface wetting them by the preparations, then were placed into the thermostst; the result was registered after their cultivasion at $37^{\circ} \mathrm{C}$ temperature for 18-24 hours there. So a sterile zone of $20 \mathrm{~mm}$ was origioned in the Eseherichia coli and dark blue and green bacillae pyogenic (hot) abscesses around the disks wetted by N.velutina and N.grosshemi. A zone of $18 \mathrm{~mm}$ was registered at Candida 22 and stafilacocc. zone of $18 \mathrm{~mm}$ was registered at Candida 22 and stafilacoc Origanum vulgare Eseherichia coli 
(bacilli) and Pseudomosa auriginosa (dark blue and green bacillae pyogenic (hot) abscesses). Also a sterile zone (vaseline saturated) was not met in controle and 5 sterile vessels were taken from the purification series methods $1 \mathrm{mgr}$ of the examined substance was flowed into the $1^{\text {st }}$ and the $2^{\text {nd }}$ bottles. $1 \mathrm{ml}$ of sterile vazeline was added into each vessel beginning from the $2^{\text {nd }}$ one. Consequently, getting $1 \mathrm{ml}$ of mixture out of the $2^{\text {nd }}$ bottle poured into the $3^{\text {rd }}$ one, getting $1 \mathrm{ml}$ of mixture out of the $3^{\text {rd }}$ into the $4^{\text {th }}$ one, getting $1 \mathrm{ml}$ of mixture out of the $4^{\text {th }}$ into the $5^{\text {th }}$ one; $1 \mathrm{ml}$ of mixture was thrown away out of the $5^{\text {th }}$ bottle. So essential oils in the sample bottles got: in the $1^{\text {st }}$ bottle - pure, i.e as it was before; in the $2^{\text {nd }}$ bottle - twice purified; in the $3^{\text {rd }}$ one 4 times purified; in the $4^{\text {th }}$ one -8 times purified; and in the $5^{\text {th }}$ bottle -16 times purified. So, after the purification a drop of the microbe suspension posessing $500 \mathrm{mln}$ microe particls in $1 \mathrm{ml}$ solid was added into each sample bottle by means of a sterile Paster pipette. Then, after the expositions for: 10 minutes, 20 minutes, 40 minutes, and 60 minutes sowing was conducted onto the nourishing medium surface located in the Petri vessel in each sample bottle. The results were registered after keeping the sowings in a thermostat under $37^{\circ} \mathrm{C}$ for 24 hours (concerning to fungi they were registered after keeping them under temerature of $28^{\circ} \mathrm{C}$ for 48 hours). The obtained results were shown in the Table 2. As it is indicated in the Table 2 this characteristics seems enough at all essential oils which antimicrobial effect were investigated. Origanum vulgare have rendered more effective anticrobial effect among them. Thereby in the case of purification of Origanum vulgare by means of vaseline oil for 4 times Eseherichia coli (bacilli) and Pseudomosa auriginosa were killed in 20 minutes, but in the case of its purification for 8 times life activity of those bacteria was stopped in 40 minutes. Only after its purification for 16 times
Origanum vulgare effected to the bacilli in an hour. Candida albicance effected onto Origanum vulgare most actively. Its purificated form for 8 times could stop development of leaven-shaped fungus in 10 minutes.

It is realised from the obtained results according to antimicrobial effect Origanum vulgare are considered as the most active preparations. That is why they can be recommended as antimicrobial substance.

\section{References}

Beydman I.N. (1974) Study methods of phenology, plants and plant associations. Novosibirsk, Nauka. p. 81-107.

Gasymov F.Y. Эфирномасличные виды рода Thymus L. Флоры Кавказа и пути их рационального использования (вопросы ресурсоведения). Автореф. Док. Дисс., 2006, Баку, 49 стр.

Ginzberg A.S. (1932) Simplified method of quantity definition of essential oils in essence-bearers. Chemical \& Pharmaceutical Industry, № 8-9, p.326329.

Goryayev M.I. (1952) Essential oils of flora the USSR. Alma-Ata: Publ/house of the Academy of Sciences of the Kazakh SSR, $378 \mathrm{p}$.

Ibadullayeva S.J., Jafarli I.A. (2007) Essential oils and aromatherapy. "ELM", Baku, p. 174

Ibrahimov G.G., Aliyev N.I., Ibrahimov S.A. (1996) Comparative data of antimicrobial effect of various essential oils onto representatives different microorganism groups. Scientific \& Practical Journal "Zdorovye", Baku, p.38-41.

Mammedova Z.A., Antimicrobial characteristics of essential oils of some species of the Nepeta L. genus Ibadullayeva S.J. Journal of Medicinal Plants Research Vol. 5(17), pp. 4369-4372, 9 September, 2011.

\section{How to cite this article:}

Agayeva, N.A., S.R. Rafiyeva, G.Sh. Shiraliyeva and Ibadullayeva, S.J. 2017. Antimicrobe Characteristics of Essential Oil of the Origanum vulgare L. Int.J.Curr.Microbiol.App.Sci. 6(12): 2214-2218. doi: https://doi.org/10.20546/ijcmas.2017.612.254 